https://doi.org/10.15407/dopovidi2021.06.023

УДК 532.54:678.027.3.002.5

А.Ф. Булат ${ }^{\mathbf{1}}$, https://orcid.org/0000-0002-6541-2140

B.I. Слiсеєв ${ }^{1}$, https://orcid.org/0000-0003-4999-8142

С.В. Семененко ${ }^{1}$, https://orcid.org/0000-0001-8707-3648

М.М. Стадничук ${ }^{\mathbf{1}}$, https://orcid.org/0000-0002-2990-9635

Б.О. Блюсс ${ }^{2}$, https://orcid.org/0000-0003-3077-1220

${ }^{1}$ Інститут геотехнічної механіки ім. М.С. Полякова НАН України, Дніпро

2 Придніпровський науковий центр НАН України та МОН України, Дніпро

E-mail: office.igtm@nas.gov.ua,VIYelisieiev@nas.gov.ua, evs_igtm@i.ua, bblyuss@gmail.com

\title{
Особливості використання малов' язкого ньютонівського середовища в екструзійному апараті для тривимірного друку
}

Представлено академіком НАН України А.Ф. Булатом

Розглядається задача про рух високов'язкої рідини у вузькому каналі з підігрівом, який моделює процес екструдування полімерів для тривимірного друку. Важливим елементом для иього класу задач є підбір параметрів руху полімерної маси та теплообміну з метою сталого формування виробу. Він полягає в тому, щоб трохи перегріту масу подати до відповідного місия, де вона швидко застигне, в результаті чого буде стійко зберігатися форма друкованого виробу. Як робоче середовище використовуються відповідні полімери, які мають необхідні властивості. У задачі, що розглядається, для розкриття фізичних особливостей процесу використовується ньютонівська рідина, яка за своїми властивостями є близькою до поліетилентерефталату (ПЕТФ), який також застосовується в технологї тривимірного друку. Задачу про рух $i$ теплообмін сформульовано в рамках теорії моделі вузького каналу з урахуванням дисипачії механічної енергіі. Для високов'язких рідин, навіть незважаючи на малі швидкості, урахування дисипативних членів $\epsilon$ необхідним, оскільки великі градієнти швидкостей можуть призводити до великої величини дисипації $i$, відповідно, до значного зростання температури. Ця особливість виявилася надзвичайно важливою саме для такого класу задач. Для більш яскравого подання розв'язку крім однієї рідини, близької до ПЕТФ, розглянуто рух і нагрів рідини, в'язкість якої у 10 разів менша за в'язкість полімеру. Розв'язання було проведено методом смуг, в яких температура i, відповідно, в'язкість, що залежить від неї, приймалися незалежними від поперечної координати. Це дозволило використовувати аналітичну залежність для швидкостей у кожній смузі, що зробило метод напіваналітичним та полегшило розв'язання задачі. Результати, отримані чисель-

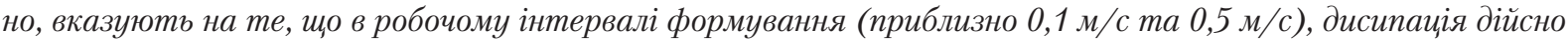
значно впливає на процес. Так, для умовно малов'язкої рідини перегрів ї̈ в кінці апарату виявляється

Ци т у в ан н я: Булат А.Ф., Єлісєєв В.І., Семененко Є.В., Стадничук М.М., Блюсс Б.О. Особливості використання малов'язкого ньютонівського середовища в екструзійному апараті для тривимірного друку. Допов. Наи. акад. наук Укр. 2021. № 6. С. 23-31. https://doi.org/10.15407/dopovidi2021.06.023 
істотним, але може бути знятий за допомогою додаткового обдування. Для високов'язкої рідини це зробити практично неможливо, тобто така рідина не може використовуватися в апараті з розглянутими геометричними розмірами. Отже, математичне моделювання досліджуваного процесу дає можливість проводити розрахунки параметрів течї та визначати необхідні умови $і$, відповідно, властивості рідини для стійкого тривимірного друкування.

Ключові слова: ньютонівська рідина, полімери, тривимірний друк, екструзійний апарат.

Основою роботи принтерів для тривимірного друку є подача та нагрів робочого тіла, яким, наприклад, є полімер, що має певні якості [1]. Полімер у вигляді порівняно тонкого твердого стрижня подається в канал, де він прогрівається, частково плавиться та виходить 3 тонкого каналу насадка на виріб, що роздруковується. Отже, найважливішим елементом процесу, який необхідно контролювати i, відповідно, моделювати, є перехід робочого матеріалу до розплавленого стану та течія його в каналі (екструдері) з урахуванням звуження в насадку та умов на виході з нього. Відомо, що полімери відносяться до фізично складних матеріалів, під час переробки яких важливу роль відіграють в’язкість та пружність [2], які в свою чергу великою мірою залежать як від молекулярного складу матеріалу, так і від надмолекулярної структури. Розроблені реологічні рівняння стану (РРС) дозволяють оцінювати якісну поведінку розплавів, проте в кількісній ще можуть помітно розходитися 3 реальними параметрами. Це деякою мірою пов’язано з неоднозначною відповідністю типових структур фізичним властивостям матеріалів, з різноманітністю конфігурацій надмолекулярних структур, а також з широким розкидом мас мономерів, які утворюють молекулярні ланцюжки. Наразі рівняння руху рідких полімерних мас, які отримали широке визнання, базуються на загальних рівняннях Нав'є-Стокса з урахуванням особливостей реологічної поведінки. У найбільш загальному вигляді для непружних рідких середовищ, придатному для розглянутого класу задач, вони наведені в [3-5].

Математична постановка задачі та іi розв'язання. Беручи до уваги, що течія відбувається в порівняно вузьких каналах, випишемо основні рівняння руху та теплообміну у спрощеній формі, яка враховує, що поперечні градієнти є значно більшими за поздовжні, тобто в рамках теорії примежового шару

$$
\begin{aligned}
& 0=-\frac{d p}{d x}+\rho g+\frac{\partial}{r \partial r}\left(\mu \frac{r \partial u}{\partial r}\right), \\
& \frac{\partial r u}{\partial x}+\frac{\partial r v}{\partial r}=0, \\
& \rho c\left(u \frac{\partial T}{\partial x}+v \frac{\partial T}{\partial r}\right)=\frac{\partial}{r \partial r}\left(r \frac{\partial q}{\partial r}\right)+\mu\left(\frac{\partial u}{\partial r}\right)^{2},
\end{aligned}
$$

де $x, r$ - циліндрична система координат; $\rho$ - густина, кг $/ \mathrm{M}^{3} ; u, v-$ швидкості, відповідно поздовжня та поперечна, м/c; $p$ - тиск, Н/м²; $T$ - температура, К; $c$ - коефіцієнт теплоємності, Дж/(кг · К); $q=\lambda(\partial T / \partial r)$ - тепловий потік, Дж/( $\left.\mathrm{м}^{2} \cdot \mathrm{c}\right) ; \mu$ - динамічний коефіцієнт в’язкості, Па · с; $\lambda$ - коефіцієнт теплопровідності, Дж/(м · c К К).

Перше рівняння є рівнянням руху без лівої конвективної частини (у подібних завданнях динамічні члени вважаються малими в порівнянні з в’язкими). Друге рівняння - це 
рівняння нерозривності, і третє - рівняння теплообміну з дисипативним членом (ефект дисипації може відігравати істотну роль в процесі).

Умова незалежності тиску від поперечної координати, характерна для теорії примежового шару, є досить натягнутою щодо течій середовищ з великими величинами в’язкості, проте це наближення часто використовується до течій у довгих тонких каналах [2, 3]. Необхідно також взяти до уваги, що для стійкої роботи під час тривимірного друку бажано розплавляти досить вузький пристінковий шар полімеру. Тому модель примежового шару може використовуватися для оцінки та аналізу динаміки процесу. Як вже зазначалося вище, розплави полімерів сильно відрізняються від простих рідин головним чином величиною своєї в'язкості. Як правило, в’язкість в реологічно складних рідинах залежить від градієнтів швидкостей, що визначає великий клас неньютонівських рідин. Однак серед полімерів є матеріали, які можуть розглядатися як ньютонівські або принаймні близькі до них рідини. Таким полімером є, наприклад, поліетилентерефталат (ПЕТФ), в'язкість розплаву якого в широкому діапазоні зміни поперечного градієнта поздовжньої швидкості залежить в основному від температури [6]. У цій статті розглянемо випадок течії цієї рідини в екструдері для 3D-друку. Крім того, розглянемо також питання про вплив величини в'язкості на процес теплообміну, точніше, про вплив дисипації на течію рідини в каналі. Необхідні характеристики цього матеріалу для розгляду поставленої задачі можуть бути знайдені в [7-10]. ПЕТФ під час швидкого формування волокон, тобто при сильному розтягуванні добре кристалізується з виділенням тепла, проте, без витягування він може залишатись аморфним. Беручи до уваги, що в екструдері є перехідна ділянка від одного циліндра до іншого, розв'язання виписаних рівнянь проведемо методом смуг. Розділимо радіус каналу на $N$ смуг, при цьому першою смугою вважатимемо прилеглу до осі каналу. Для спрощення розв'язання приймемо також, що в кожній смузі температура рідини є постійною, відповідно постійною є також в’язкість. У цьому випадку рівняння (1) для кожної смуги може бути переписано у вигляді

$$
0=-\frac{d p}{d z}+p g+\mu_{J} \frac{\partial}{r \partial r}\left(\frac{r \partial u_{J}}{\partial r}\right),
$$

де $j$ - номер смуги. Простим інтегруванням можна отримати швидкість у $j$-й смузі

$$
u_{j}=\frac{R^{2}}{4 \mu_{j}}\left(\frac{\partial p}{\partial z}-p g\right) n^{2}+a_{j} \ln n+b_{j},
$$

де $n=r / R ; a_{j}$ та $b_{j}-$ сталі інтегрування.

Будемо розглядати випадок, коли температура стінки каналу є постійною та незначно перевищує температуру плавлення полімеру. Приймемо далі, що до точки плавлення (під точкою плавлення будемо розуміти точку, в якій відповідно до нашої умови щодо в'язкості середня температура рідини в смузі, що прилягає до стінки, стає рівною температурі стінки) швидкість стрижня є постійною та дорівнює деякій початковій швидкості $U_{C}$, тобто у виразі (5) два перших члени дорівнюють нулю, а $b_{j}=U_{C}$.

Після точки плавлення приймаємо:

- швидкість на стінках каналу дорівнює нулю; 
- на межах смуг виконуються умови рівності швидкостей $u_{j}$ та дотичних напружень;

- на осі трубки виконується умова симетрії, тобто напруга тертя дорівнює нулю.

3 цих умов випливає, що $a_{j}=0$,

$$
b_{N}=-\frac{R^{2}}{4 \mu_{N}}\left(\frac{\partial p}{\partial z}-\rho g\right) \quad \text { та } \quad b_{j-1}=b_{j}+\frac{R^{2}}{4}\left(\frac{\partial p}{\partial z}-\rho g\right)\left(\mu_{j}^{-1}-\mu_{j-1}^{-1}\right) n_{j-1}^{2} .
$$

За допомогою формули (5) можна визначити середню швидкість у смузі $U_{J}$ та об’ємну витрату рідини

$$
Q_{j}=\frac{1}{2}\left(n_{j}^{2}-n_{j-1}^{2}\right) R^{2} U_{J}=R^{2}\left[\frac{R^{2}}{16 \mu_{j}}\left(\frac{\partial p}{\partial z}-\rho g\right)\left(n_{j}^{4}-n_{j-1}^{4}\right)+b_{j} \frac{1}{2}\left(n_{j}^{2}-n_{j-1}^{2}\right)\right]
$$

З урахуванням того, що маса рідини в каналі має залишатися постійною, необхідно виконати умову

$$
Q=\frac{1}{2} R^{2} U_{C}=\sum_{j=1}^{N} Q_{j}
$$

тобто сума об’ємних витрат у смугах дорівнює повній об’ємній витраті полімеру (рідину вважаємо повністю нестисливою). Ця рівність служить для визначення градієнта тиску уздовж осі каналу.

Розглянемо теплову задачу. Інтегруючи рівняння (2) та (3) за радіусом у смузі, отримаємо такі вирази:

$$
\begin{aligned}
& \frac{d}{d x} R^{2} \int_{n_{j-1}}^{n_{j}} n u d n+R\left(n_{j} v_{j}-n_{j-1} v_{j-1}\right)-\left(n_{j} u_{g j}-n_{j-1} u_{g j-1}\right) \frac{d R}{d x}=0 \\
& p c\left(\frac{d}{d x} R^{2} \int_{n_{j-1}}^{n_{j}} n u T d n+R\left(n_{j} v_{j} T_{j}-n_{j}-n_{j-1} v_{j-1} T_{j-1}\right)\right)= \\
& =R\left(n_{j} q_{j}-n_{j-1} q_{j-1}\right)+\frac{R^{4}}{16 \mu_{j}}\left(\frac{\partial p}{\partial z}-\rho g\right)^{2}\left(n_{j}^{4}-n_{j-1}^{4}\right)
\end{aligned}
$$

де параметри з індексом $g$ є величинами на межах смуг.

3 огляду на те, що температура у смузі вважається незалежною від радіуса, як було вище домовлено, перепишемо рівняння (10) у вигляді

$$
\begin{aligned}
& p c\left(Q_{j} \frac{d T_{j}}{d x}+R n_{j}\left(u_{g j} n_{j} \frac{d R}{d x}-v_{g j}\right)\left(T_{j}-T_{g j}\right)\right)-R n_{j-1}\left(u_{g j-1} n_{j-1} \frac{d R}{d x}-v_{g j-1}\right)\left(T_{j}-T_{g j-1}\right)= \\
& =R\left(n_{j} q_{j}-n_{j-1} q_{j-1}\right)+\frac{R^{4}}{16 \mu_{j}}\left(\frac{\partial p}{\partial z}-\rho g\right)^{2}\left(n_{j}^{4}-n_{j-1}^{4}\right) .
\end{aligned}
$$




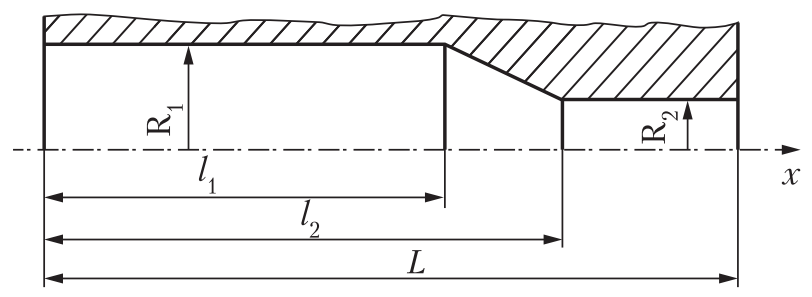

Puc. 1. Схема каналу екструзійного апарата

Величини теплових потоків визначимо як

$$
q_{j}=-2 \lambda_{j} \frac{T_{j}-T_{g j}}{R\left(n_{j}-n_{j-1}\right)} .
$$

При цьому необхідно, щоб температури та теплові потоки на межах смуг були рівними, тому між середніми температурами у смугах та на межах виконуються прості співвідношення

$$
T_{g j}=\frac{\lambda_{j}}{\lambda_{j}+\lambda_{j+1}} T_{j} \frac{\lambda_{j+1}}{\lambda_{j}+\lambda_{j+1}} T_{j+1} \quad \text { i } \quad q_{j}=-\frac{2}{R\left(n_{j}-n_{j-1}\right)} \frac{\lambda_{j} \lambda_{j+1}}{\lambda_{j}+\lambda_{j+1}}\left(T_{j}-T_{j+1}\right) .
$$

У розрахунках приймемо, що коефіцієнт теплопровідності не залежить від температури. Тоді ці формули ще більш спростяться. Запропонований у статті метод розрахунку є напіваналітичним і зручним для встановлення якісних залежностей модельованих величин від геометричних розмірів екструзійного апарата та основних визначальних параметрів, якими є швидкість подачі матеріалу, його початкова температура, реологічні залежності та теплофізичні параметри.

Результати розрахунків. Під час розгляду цих завдань цікавим є питання про швидкість подачі полімерного стрижня до екструдера. Тому були розраховані два основних варіанти, коли швидкість була малою і, відповідно, порівняно великою (в нашому випадку $U_{C}=0,001 \mathrm{~m} / \mathrm{c}$ та $0,005 \mathrm{~m} / \mathrm{c}$ ). У розрахунках були прийняті такі величини (рис. 1): радіус широкої частини $R_{1}=0,001 \mathrm{~m}$; радіус вузької частини $R_{2}=0,0002$ м; довжина робочої частини $L=0,2$ м; довжина широкої циліндричної частини $l_{1}=0,17$ м; довжина каналу до вузької частини $l_{2}=0,19$ м; $\zeta=x / L-$ відносна довжина каналу; $\rho=1380$ кг $/ \mathrm{m}^{3} ;$ початкова температура стрижня $T_{C}=293 \mathrm{~K}$; температура плавлення $T_{P}=533 \mathrm{~K}$; температура стінки $T_{W}=535 \mathrm{~K}$; $c=1260$ Дж / (кг $\cdot$ К); $\mu=\beta / 3 ;$ ньютонівська в’язкість $\beta=0,725 \cdot \exp (5260 /$ Т) Па $\cdot$; $\lambda=0,14$ Дж/(м · $\cdot$ К $)$; полімери є аморфними, прихованою теплотою фазових переходів нехтуємо.

Для визначення впливу динамічної в’язкості на рух і теплообмін крім варіанту з ПЕТФ були проведені розрахунки для випадку матеріалу з умовно заниженою в 10 разів в’язкістю. Результати цих розрахунків проілюстровано на рис. 2-4.

На рис. 2. показано профілі швидкостей течії полімерів при подачі стрижня зі швидкістю 0,001 м/с. Для такої швидкості, як видно з рис. 2, a і 2, б, криві швидкостей як в найширшій частині екструдера, так і у вузькому насадку за різних значень коефіцієнтів динамічної в’язкості практично збігаються одна з одною (наявні невеликі відмінності в масштабах рисунка не проглядаються). На рис. 2, а добре видно, як профіль швидкості стрижня в обох варіантах $(1,4)$ швидко перебудовується в криву $(2,5)$, а потім в криву $(3,6)$, ха- 

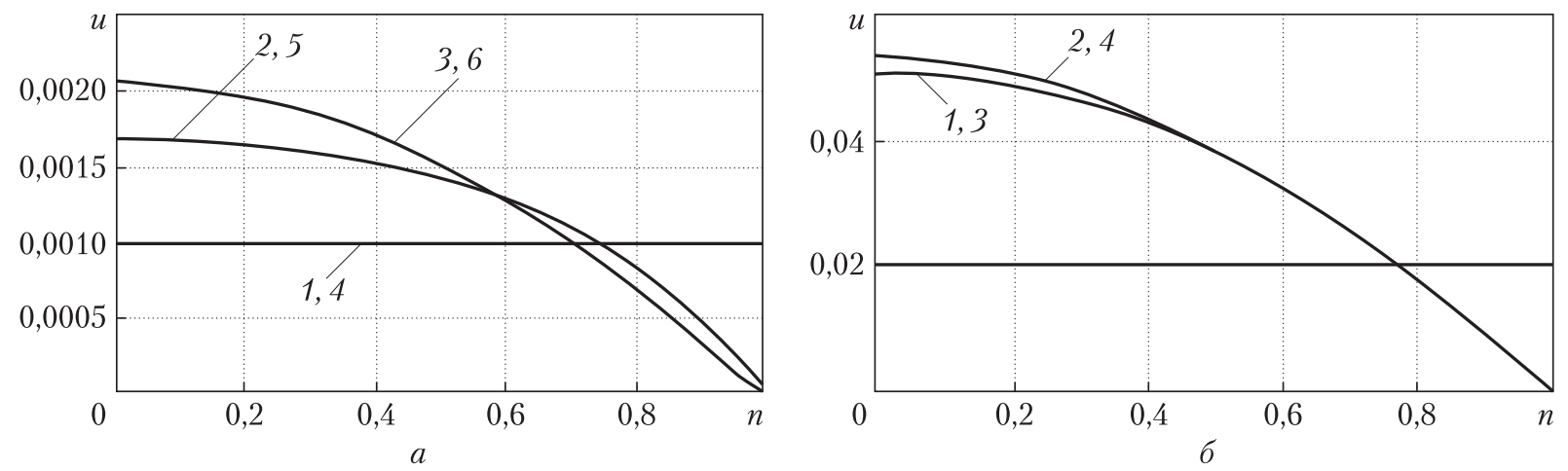

$\boldsymbol{P} \boldsymbol{u c}$. 2. Профілі поздовжніх швидкостей $u$ (м/с) у поперечних перетинах каналу екструдера, $U_{C}=0,001 \mathrm{~m} / \mathrm{c}$ : $a-$ широка частина каналу (криві $1,4-\zeta_{1}=0,002 ; 2,5-\zeta_{2}=0,02 ; 3,6-\zeta_{3}=0,85$ ), номери $1-3$ відносяться до I варіанта, тобто до ПЕТФ, 4-6 - до II варіанта; 6 - насадок (криві 1,3- $\zeta_{4}=0,95 ; 2,4-\zeta_{5}=1$ ), номери 1, 2 відносяться до I варіанта, 3, 4 - до II.
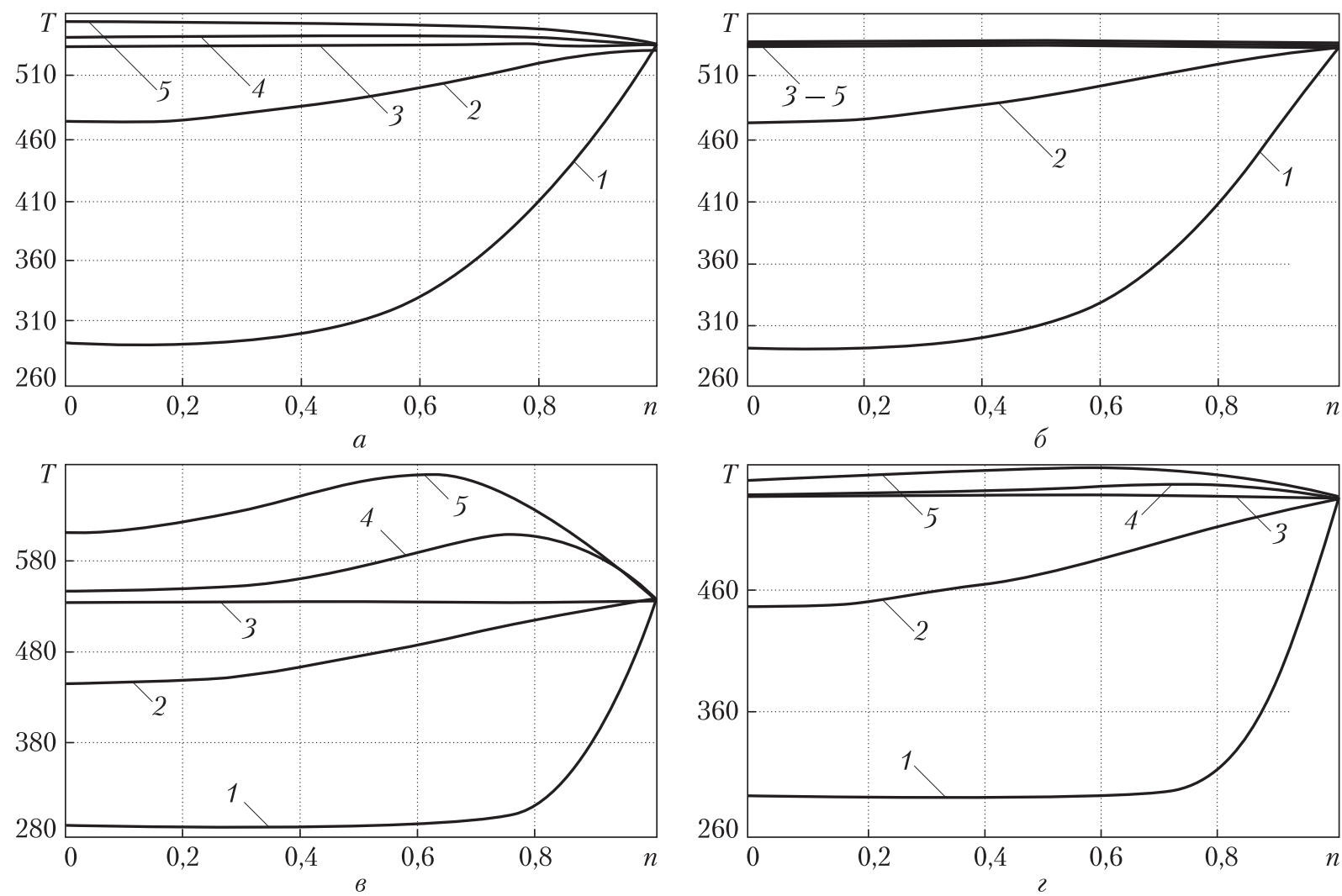

Puc. 3. Профілі температур $T$ (К) у поперечних перетинах каналу екструдера: $a-$ випадок з ПЕТФ, $U_{C}=0,001 \mathrm{~m} / \mathrm{c} ; \sigma-$ зі зниженою в'язкістю (криві $1-\zeta_{1}=0,002 ; 2-\zeta_{2}=0,02 ; 3-\zeta_{3}=0,85 ; 4-\zeta_{4}=0,95$; $\left.5-\zeta_{5}=1\right), U_{C}=0,001 \mathrm{~m} / \mathrm{c} ;$ в - випадок з ПЕТФ (криві $1-\zeta_{1}=0,002 ; 2-\zeta_{2}=0,0784 ; 3-\zeta_{3}=0,85$; $\left.4-\zeta_{4}=0,95 ; 5-\zeta_{5}=1\right), U_{C}=0,005 ; 2-$ другий варіант (криві $1-5$ відповідають тим самим перетинам, що й на рис. $3, a), U_{C}=0,005$. 

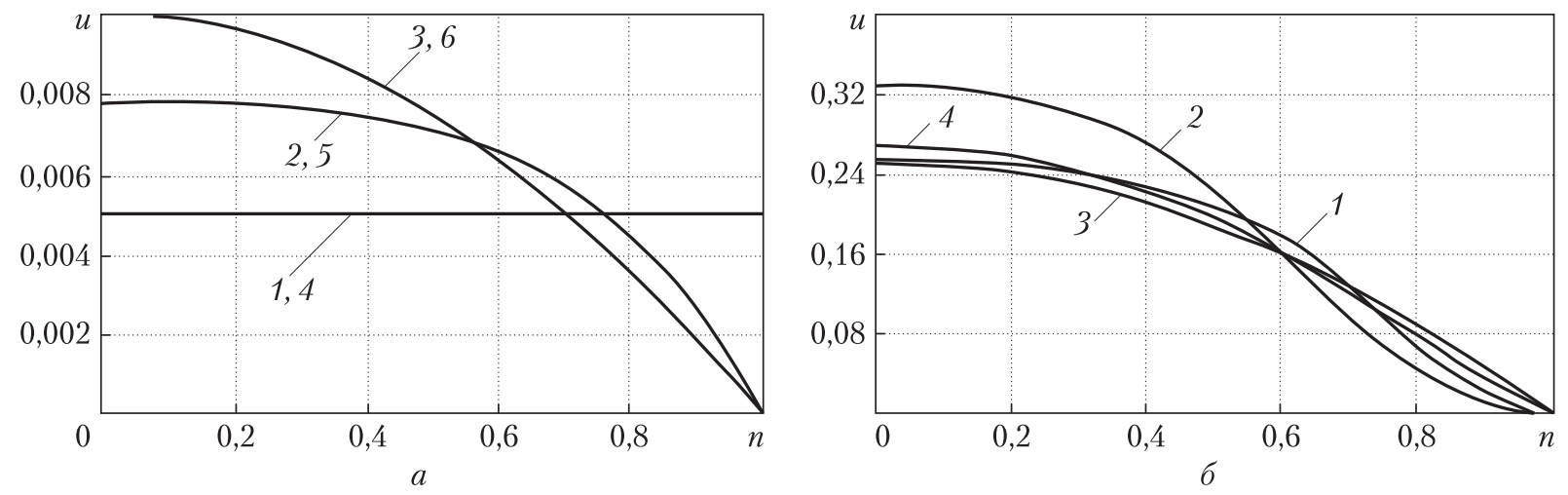

Puc. 4. Профілі поздовжніх швидкостей $u$ (м/с) у поперечних перетинах каналу екструдера, $U_{C}=$ $=0,005 \mathrm{~m} / \mathrm{c}: a-$ широка частина каналу (криві $1,4-\zeta_{1}=0,002 ; 2,5-\zeta_{2}=0,0784 ; 3,6-\zeta_{3}=0,85$ ), номери 1-3 відносяться до I варіанта, тобто до ПЕТФ, 4-6 - до II варианта; 6 - насадки (криві 1, $3-\zeta_{4}=0,95$; 2, $\left.4-\zeta_{5}=1\right)$; номери 1, 2 відносяться до I варіанта, 3, 4 - до II.

рактерну для течії рідини в каналі. У вузькому насадку (рис. 2, б) швидкість рідини сильно збільшується відповідно до закону збереження маси.

Профілі температур у поперечних перетинах представлено на рис. 3. 3 них видно, як увігнуті криві переходять до опуклих. Справа в тому, що в початкових перетинах, коли температура стінки є вищою за температуру стрижня, тепловий потік надходить всередину матеріалу. За появи великих градієнтів поздовжньої швидкості виділяється теплова енергія, яка особливо у вузькій частині насадка швидко поширюється по внутрішній зоні течії, внаслідок чого температура тут зростає (в масштабах рисунка криві 3 та 5 на рис. 3, 6 практично зливаються). На стінці ж, з огляду на сталість температури поверхні каналу, тепло починає відходити, в результаті профіль стає опуклим. Максимальні температури в цих варіантах досягають величин 553 К і 537 К відповідно. Таким чином, видно, що ПЕТФ на виході з екструдера навіть за порівняно невеликої швидкості подачі матеріалу перегрівається на помітну величину, що має позначитися на стійкості друкованого виробу.

Хоча вже за швидкості $U_{C}=0,001 \mathrm{~m} /$ с величина дисипації справляє помітний вплив на температуру розплаву і робить процес практично нереальним для даної геометрії каналу без додаткового відбору тепла, становить інтерес розглянути випадок з високою швидкістю подачі матеріалу, в якому дисипація проявляється найбільш яскраво . На рис. 4 наведено криві швидкостей у поперечних перетинах для тих самих матеріалів. У широкій частині екструдера, як і на рис. 2, $a$, спостерігається збіг кривих через масштаб рисунка. У вузькій частині (рис. 4, б) ці криві вже помітно розходяться, тобто тут величини в'язкості у смужках вже мають велику відмінність відносно одна одної.

Профілі температур показано на рис. 3, в та 3, г. Тут добре видно, що до моменту зменшення радіуса каналу температури вирівнюються по перетину, а потім при звуженні каналу швидкість рідини зростає та, відповідно, зростають поперечні градієнти швидкостей, збільшується виділення теплової енергії та профілі температур починають сильно вигинатися. При цьому навіть у вузькій частині на виході з каналу на відміну від малої швидкості подачі теплові потоки не встигають повністю передати енергію всередину матеріалу, через що профілі мають яскраво виражені підйоми. 
Максимальні температури - 669 К та 559 К значною мірою перевищують температуру плавлення. Таким чином, з розрахунків видно, що в’язкість матеріалу відіграє істотну роль у процесі. Це означає, що швидкість подачі матеріалу повинна бути узгоджена з процесами теплопередачі.

Висновки. В рамках моделі вузького каналу розглянуто задачу про нагрівання та рух рідини з великою в'язкістю, що залежить від температури. Отримані профілі швидкостей та температур свідчать про значний вплив дисипативних чинників на процес екструдування. Результати розрахунків указують на те, що швидкість подачі матеріалу повинна бути узгоджена з теплообміном, за необхідності з урахуванням організованого тепловідбору.

\section{ЦИТОВАНА ЛІТЕРАТУРА}

1. Шкуро А. Е., Кривоногов П. С. Технологии и материалы 3D-печати: учебное пособие. Екатеринбург: УГЛТУ, 2017. $101 \mathrm{c.}$

2. Чанг Дей Хан. Реология в процессах переработки полимеров. Москва: Химия, 1979. 366 с.

3. Ким В. С. Теория и практика экструзии полимеров. Москва: Химия, 2005. 568 с.

4. Кузяев И. М., Свидерский В. А., Петухов А. Д. Моделирование экструзии и экструдеров при переработке полимеров. Ч. 1. Киев: Политехника, 2016. 414 с.

5. Ревяко М. М., Прокопчук Н. Р. Теоретические основы переработки полимеров. Минск: БГТУ, 2009. $305 \mathrm{c}$.

6. Теплофизические и реологические характеристики полимеров: Липатова Ю. С. (ред.). Киев: Наук. думка, 1977. $244 \mathrm{c.}$

7. Высокоскоростное формование волокон: Зябицкого А., Каваи Х. (ред.). Москва: Химия, 1988. 488 с.

8. Елисеев В. И., Совит Ю. П., Флер Л. А. Численное моделирование формования пучков волокон из расплавов полимера. Прикл. механика и техн. физика. 1999. 40, № 1. С. 184-192.

9. Блюсс Б. А., Никифорова Н. А., Витушко О. В. Моделювання електров’язкістного ефекту при фільтрації рідини в гірських породах. Геотехн. механіка. 2012. № 101. С. 187-192.

10. Пристрій для лазерного тривимірного друку: пат. №124376 Україна. МПК B41J2/00 G02B26/12 H04N1/113 (2006.1). Булат А. Ф., Возіянов В. С., Стадничук М. М., Волошин О. І., Губенко Д. І., Кутимов І. В. № u201709433; заяв. 26.09.2017. Опубл. 10.04.2018.

11. Семененко Е. В., Киричко С. Н. Математическая модель безнапорного течения неньютоновской жидкости. Проблеми мат. моделювання. 2014. С. 86-88.

Надійшло до редакції 06.07.2021

\section{REFERENCES}

1. Shkuro, A. E. \& Krivonogov, P. S. (2017). Technologies and materials for 3D printing: tutorial, Ekaterinburg: UGLTU (in Russian).

2. Chang Dey Han (1979). Rheology in polymer processing. Moscow: Himiya (in Russian).

3. Kim, V. S. (2005). Theory and practice of polymer extrusion. Moscow: Himiya (in Russian).

4. Kuzyaev, I. M., Sviderskiy, V. A. and Petuhov, A. D. (2016). Simulation of extrusion and extruders in polymer processing. Pt.1, Kiev: Politehnika (in Russian).

5. Revyako, M. M. \& Prokopchuk, N. R. (2009). Theoretical foundations of polymer processing. Minsk: BGTU (in Russian).

6. Lipatova, Yu. S. (Ed.) (1977). Thermophysical and rheological characteristics of polymer. Kiev: Naukova Dumka (in Russian).

7. Zyabitskogo, A. (ed.) \& Kavai, H. (Ed.) (1988). High speed fiber spinning. Moscow: Himiya (in Russian).

8. Yelisieiev, V. I., Sovit, Yu. P. \& Fler, L. A. (1999). Numerical simulation of the formation of fiber bundles from polymer melts. Appl. Mech. and Techn. Phys., 40, No. 1, pp. 184-192 (in Russian).

9. Blyuss, B. A., Nykyforova, N. A. \& Vytushko, O. V. (2012). Simulation of the electroviscous effect in fluid filtration in rocks. Geotech. mech., № 101, pp. 187-192 (in Ukrainian). 
10. Pat. 124376 UA, IPC B41J2/00 G02B26/12 H04N1/113 (2006.1), Device for three-dimensional laser printing, Bulat, A.F., Voziianov, V. S., Stadnychuk, N. N., Voloshyn, O. I., Hubenko, D. I., Kutymov, I. V. № u201709433; Publ. 10.04.2018 (in Ukrainian).

11. Semenenko, Ye. V. \& Kyrychko, S. N. (2014). Mathematical model of free flow of non-Newtonian fluid. Problems of math. modeling, pp. 86-88 (in Russian).

Received 06.07.2021

A.F. Bulat ${ }^{1}$, https://orcid.org/0000-0002-6541-2140

V.I. Yelisieiev ${ }^{1}$, https://orcid.org/0000-0003-4999-8142

Ye.V. Semenenko ${ }^{1}$, https://orcid.org/0000-0001-8707-3648

N.N. Stadnychuk ${ }^{1}$, https://orcid.org/0000-0002-2990-9635

B.A. Blyuss ${ }^{2}$, https://orcid.org/0000-0003-3077-1220

${ }^{1}$ M.S. Poljakov Institute of Geotechnical Mechanics of the NAS of Ukraine, Dnipro

${ }^{2}$ Prydniprovsky Research Center of the NAS of Ukraine and MES of Ukraine, Dnipro

E-mail: office.igtm@nas.gov.ua, VIYelisieiev@nas.gov.ua, evs_igtm@i.ua, bblyuss@gmail.com

FEATURES OF USING A LOW-VISCOSITY NEWTONIAN MEDIUM

IN AN EXTRUSION APPARATUS FOR THREE-DIMENSIONAL PRINTING

This research aims to investigate the motion of a high-viscosity liquid in a narrow heated channel simulating the process of extrusion of polymers for the three-dimensional printing. The selection of polymer mass movement and heat exchange parameters is an important element for this type of tasks. Its purpose is to obtain a stable product molding. Here, it consists in feeding the slightly overheated mass to the appropriate place, where it will quickly solidify; therefore the printed product shape is stably retained. Corresponding polymers with the required properties are used as a working medium. A Newtonian liquid is used to reveal the physical features of the process. Its properties are close to those of polyethylene terephthalate, which is also used in the three-dimensional printing technology. The problem of motion and heat exchange is formulated within the framework of the narrow channel model theory with regard for the mechanical energy dissipation. It is necessary to consider the dissipative terms, since large velocity gradients can lead to a large value of the dissipation and, accordingly, to a large increase in the temperatures. The feature turns out to be extremely important for this particular task type. In addition to a liquid close to PETF, the motion and heating of a liquid, the viscosity of which is 10 times less than the viscosity of the polymer, is considered for a clearer presentation of the resilts. The solution was carried out using the method of stripes, in which the temperature and, accordingly, the viscosity, depending on it, are taken independent of the cross-coordinate. This makes it possible to use an analytical dependence for the velocities in each stripe, which makes the method semianalytical and facilitates the solution. The results obtained numerically indicate that, within the working interval of the molding (about $0.1 \mathrm{~m} / \mathrm{s}$ and $0.5 \mathrm{~m} / \mathrm{s}$ ), the dissipation has a really significant effect on the process. So, the overheating of a conventionally low-viscosity liquid at the end of the apparatus turns out to be significant, but it can be removed by the additional blowing. This is practically impossible to do for a highly viscous fluid, i.e. such a liquid cannot be used in an apparatus with the considered geometrical dimensions. Thus, the mathematical modeling of the process under study makes it possible to calculate the flow parameters and to determine the necessary conditions and, accordingly, the properties of the liquid for a stable three-dimensional printing.

Keywords: Newtonian fluid, polymers, three-dimensional printing, extrusion apparatus. 